Technical Report 5-20333 \& 5-20334

Contract No. DAAH01-98-D-R001

Delivery Order No. 26

\title{
Manufacturing Technology Transfer \\ Support
}

(5-20333 \& 5-20334)

Final Technical Report for Period

29 September 98 through 31 March 1999

October 1999

Prepared by:

Gary A. Maddux

Research Institute

The University of Alabama in Huntsville Huntsville, Alabama 35899

Prepared for:

U.S. Army Aviation \& Missile Command Redstone Arsenal, AL 35898

Attn.: Mr. Martin Harris 


\section{REPORT DOCUMENTATION PAGE}

Public reporting burden tor this collection of information is estimated to average I hour per rexooms. including the time for reviewing instructions. searching existing data sources. Public reporting burden for the catle needed. and completing and reviewing the collection of intormation. Seno comments regarding this burden estimate or any other aspect of this collertion of information, including suggestions for reducing this burden. to Washington heacover. Pacerwork Reduction Project (O704-0 188), Washington, DC 20503. Davis Highway, Suite 1204, Arlington, VA 22202-4302. and to the OHice of
1. AGENCY USE ONLY (Leave blank)
2. REPORT DATE
3. REPORT TYPE AND DATES COVERED

\section{TITLE AND SUBTITLE}

Manufacturing Technology Transfer Support

\section{AUTHOR(S)}

Gary A. Maddux

\section{PERFORMING ORGANIZATION NAME(S) AND ADDRESS(ES)}

Univ. of Alabama in Huntsville

Huntsville, AL 35899

\section{FUNDING NUMBERS}

\section{SPONSORING/MONITORING AGENCY NAME(S) AND ADDRESS(ES)}

AMSAM-RD-SE-MT (M. HARRIS)

U.S. Army Aviation \& Missile Command

Redstone Arsenal, AL 35898

\section{PERFORMING ORGANIZATION} REPORT NUMBER

5-20333 \& 5-20334

\section{SUPPLEMENTARY NOTES}

\section{DISTRIBUTION/AVAILABILITY STATEMENT}

Approved for Public Release; Distribution is unlimited.

\section{SPONSORING IMONITORING} AGENCY REPORT NUMBER

\section{ABSTRACT (Maximum 200 words)}

The Systems Engineering and Production Directorate (SEPD) has the mission and function of evaluating The Systems Engineering and Products of same on the producity and supportability of AMCOM new technologies and determining missile systems. The Manufacturing Science and TMCOM systems. Engineering support was needed to in several key product / process areas to support AMCOM systems. Engineering support was needed transfer new product / process technologies to the industrial base for applications that reduce AMCOM systems cost and cycle time. AMCOM required engineering support in performing technology transfer of three specific technologies. The Systems Management and Production Laboratory at The University of Alabama in Huntsville (UAH) Research Institute (RI) was tasked to provide this engineering support and technology capability.

\section{SUBJECT TERMS}

technology transfer, data compression

17. SECURITY CLASSIFICATION OF REPORT
18. SECURITY CLASSIFICATION OF THIS PAGE
19. SECURITY CLASSIFICATION OF ABSTRACT
15. NUMBER OF PAGES

16. PRICE CODE 


\section{PREFACE}

This technical report was prepared by the staff of the Research Institute, The University of Alabama in Huntsville. The purpose of this report is to provide documentation of the work performed and results obtained under Delivery Order 26 of AMCOM Contract No. DAAH01-98-D-R001. Mr. Gary Maddux was the principal investigator. Mr. Martin Harris, Manufacturing Science and Technology Division, Research, Development, and Engineering Center, U.S. Army Aviation \& Missile Command, provided technical coordination.

The views, opinions, and/or findings contained in this report are those of the author(s) and should not be construed as an official Department of the Army position, policy, or decision unless so designated by other official documentation.

Except as provided by the Contract Data Requirements List DD Form 1423, hereof, the distribution of any contract report in any state of development or completion is prohibited without the approval of the Contracting Officer.

Prepared for: Commander

U.S. Army Aviation \& Missile Command

Redstone Arsenal, AL 35898

I have reviewed this report, dated October 1999 and the report contains no classified information.

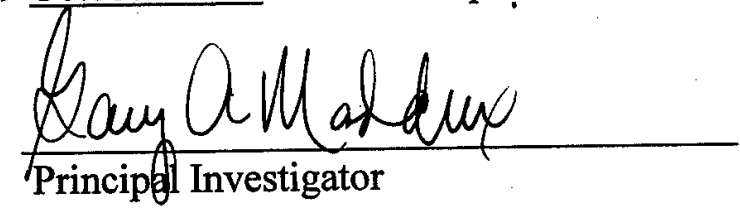


TABLE OF CONTENTS

1.0 INTRODUCTION.........................................................

2.0 OBJECTIVES ….....................................................

3.0 STATEMENT OF WORK ..............................................

4.0 TECHNOLOGY TRANSFER ACTIVITIES .............. 2

5.0 CONCLUSIONS AND RECOMMENDATIONS ............... 2

ii. 


\subsection{Introduction}

The Systems Engineering and Production Directorate (SEPD) has the mission and function of evaluating new technologies and determining the impacts of same on the producibility and supportability of AMCOM missile systems. The Manufacturing Science and Technology Division within SEPD is conducting research in several key product / process areas to support AMCOM systems. Engineering support was needed to transfer new product / process technologies to the industrial base for applications that reduce AMCOM systems cost and cycle time.

AMCOM required engineering support in performing technology transfer of three specific technologies. The Systems Management and Production Laboratory at The University of Alabama in Huntsville (UAH) Research Institute (RI) was tasked to provide this engineering support and technology capability.

\subsection{Objective}

The objective of this research task was to develop a technology transfer mechanism to disseminate findings of the SEPD Manufacturing Science and Technology Division to key players within the defense industry. Investigation of the most appropriate electronic media was required, along with the development of a software interface to enhance user interaction.

\subsection{Statement of Work}

The statement of work, as outlined in delivery order 26, was as follows:

UAH shall provide the resources required to perform the efforts described in this statement of work. This effort encompasses aviation and missile manufacturing technologies, computer tools and processes for secure manufacturing data sharing over the Internet, multi-media data presentation on compact disk, and engineering analysis of data compression techniques for missile guidance.

3.1 Computer tools and processes for secure manufacturing data sharing. UAH shall develop new secure information system techniques and software tools to demonstrate electronic collaboration concepts. The Internet shall be used as the networking medium to integrate geographically distributed teams. Secure data transfer utilities shall be developed and demonstrated along with utilities for server management, multi-media data presentation, and multi-function databases. Efforts shall be limited to the Manufacturing Science and Technology Division's computer network. 
3.2 Multi-media data presentation on compact disk for technology transfer. UAH shall develop a computer compact disk to present Manufacturing Technology (MANTECH) data in multi-media format (video, text, images, and interactive links to Internet sites). The Government will provide MANTECH data for 20 projects, and UAH shall convert the data into multi-media formats and develop the utilities necessary for user-friendly viewing on standard personal computers. Approximately two hundred disks shall be provided for distribution.

3.3 Engineering analysis of data compression techniques for missile guidance. UAH shall support a Government-hosted workshop on data compression to provide data analysis, coordination of research materials, and distribution of materials on a computer compact disk. Approximately one hundred disks shall be provided for distribution to workshop attendees.

\subsection{Technology Transfer Activities}

The work performed on Tasks 3.1 and 3.2 were completed and delivered to the Manufacturing Science and Technology Division on CD-ROM under separate cover. The work performed on Task 3.3 led directly to the Workshop on Data Compression Techniques, which was held at the Sparkman Center Auditorium in Huntsville, Alabama. The objective of this workshop was to review the progress of data compression technologies applicable to DoD weapon systems.

\subsection{Conclusion and Recommendations}

During the time frame allocated by the delivery order, members of the UAH Systems Management and Production Lab, with the cooperation of representatives from AMCOM SEPD, performed an analysis and evaluation of data compression technologies and technology transfer methodologies. Results of these efforts were presented at a locally held workshop. Detailed findings can be found in the proceedings of that workshop, which was compiled by UAH and delivered under separate cover. 